\title{
HISTÓRIA LOCAL E (RE) CONSTRUÇÃO DE IDENTIDADES
}

\author{
José Antonio Moraes do Nascimento* \\ Erica Karnopp** \\ Bianca Tamara de Siqueira***
}

RESUMO: O artigo apresenta discussões a respeito da importância da História Local como método de abordagem ao longo do Ensino Fundamental, para constituir-se como uma ferramenta que possibilita a (re) construção, ou identificação das identidades locais, considerando os elementos culturais, para que vise suavizar os impactos do processo de globalização sob as identidades. Caracteriza-se por ser uma pesquisa qualitativa, sob o método relativista, que entrevistou professores e gestores que atuam em escolas públicas municipais e estaduais dos municípios de Herveiras e Rio Pardo, do estado do Rio Grande do Sul. Os resultados mostram que a História Local tem um papel significativo na Educação Patrimonial e na construção das memórias que levam ao relevante processo de construção das identidades.

PALAVRAS-CHAVE: História Local; Cultura; Ensino.

\section{Local history and (re) construction of identities}

ABSTRACT: This text presents discussions about the importance of Local History as a method of approach throughout Elementary School, to constitute itself as a tool that allows the (re) construction, or identification of local identities, considering cultural elements, to that aims to smooth the impacts of the globalization process under the identities. It is characterized by a qualitative research, under the relativistic method that interviewed teachers and managers who work in public municipal and state schools in the municipalities of Herveiras and Rio Pardo, in the state of Rio Grande do Sul. The results show that Local History has a significant role in Heritage Education and in the construction of memories that lead to the relevant process of construction of identities.

KEY WORDS: Local History; Patrimonialização; Culture; Teaching.

\section{Historia local y (re) construcción de identidades}

RESUMEN: El artículo presenta discusiones sobre la importancia de la Historia Local como método de abordaje a lo largo de la Escuela Primaria, para constituirse como una herramienta que permita la (re) construcción, o identificación de identidades locales, considerando los elementos culturales, para lo cual se pretende suavizar los impactos del proceso de globalización bajo las identidades. Se caracteriza por ser una investigación cualitativa, bajo el método relativista, que entrevistó a docentes y gerentes que laboran en escuelas públicas municipales y estatales de los municipios de Herveiras y Rio Pardo, en el estado de Rio Grande do Sul. Los resultados muestran que Local La historia tiene un papel significativo en la Educación Patrimonial y en la construcción de memorias que conducen al relevante proceso de construcción de identidades.

PALABRAS CLAVE: Historia local; Cultura; Enseñando.

*Doutor em História pela Pontifícia Universidade Católica do Rio Grande do Sul. Professor do Programa de Pós-Graduação em Desenvolvimento Regional e dos Cursos de História e Geografia da Universidade de Santa Cruz do Sul. Contato: Unisc, Bloco 3, Sala 305. Av Independencia, 2293, Bairro Universitário, Santa Cruz do Sul-RS, Brasil, CEP 96815-900. E-mail: josenasc@ unisc.br. ORCID: http://orcid.org/0000-0002-0083-1918

**Doutora em Geografia pela Universität Tübingen - Alemanha (Eberhard-Karls Universität). Professora do Programa de Pós-Graduação em Desenvolvimento Regional e do Curso de Geografia da Universidade de Santa Cruz do Sul. Contato: Unisc, Bloco 3, Sala 305. Av Independencia, 2293, Bairro Universitário, CEP 96815900Santa Cruz do Sul-RS. E-mail: erica@unisc.br. ORCID http://orcid.org/0000-0002-2335-0295

***Mestra em Desenvolvimento Regional pela Universidade de Santa Cruz do Sul. Professora de História e Geografia para Ensino Fundamental na rede municipal de Sinimbu. Contato: Unisc, Bloco 3, Sala 305. Av Independencia, 2293, Bairro Universitário, CEP 96815-900 Santa Cruz do Sul-RS, Brasil. E-mail: biancasiqueira10@hotmail.com. ORCID http://orcid.org/0000-0003-0120-987X 
O presente trabalho pretende abordar as possibilidades de utilização do ensino de História Local como um método na construção de conhecimento de um determinado lugar, como construtor da cidadania e norteador dos processos de (re) construção de sua identidade. Para isso, como base empírica, serão apresentadas considerações sobre a forma de abordagem e os impactos da História Local nos sistemas educativos municipais e estaduais de Herveiras e Rio Pardo-RS.

Para a seleção desses municípios, a independência administrativa de ambos foi levada em consideração, sendo que Herveiras se emancipou em 1995 e Rio Pardo, por sua vez, teve a sua vila elevada à categoria de cidade em 1846, ou seja, quase 150 anos de diferença. Assim, considerando que o primeiro apresenta uma independência administrativa recente, a escolha objetiva compreender como municipalidades tão jovens e sem narrativa histórica consolidada dão conta (ou não) de ensinar a sua História Local e de que maneira o fazem. Já em relação a Rio Pardo, como é um dos quatro municípios mais antigos do estado, com significativas ligações históricas, também se questiona sobre a preocupação (ou não) em contemplar o ensino de História Local, nas redes de ensino.

Portanto, considerando as distintas realidades, a partir de uma abordagem qualitativa, sob a análise relativista, composta com técnicas de entrevista semiestruturada e revisão bibliográfica, foi realizada uma reflexão a respeito da concepção teórica sobre o ensino de História Local e as suas contribuições na (re) construção identitária. Para compreender esse processo, foram entrevistados professores do $4^{\circ}$ ao $9^{\circ}$ ano do Ensino Fundamental, que naquele momento eram responsáveis pela disciplina de História na escola. O foco de observação nos professores se justifica porque são os principais mobilizadores do ensino, em sua arte de preparar e ministrar aulas. As entrevistas ocorreram entre os meses de maio e agosto de 2019, e a duração variou entre falas curtas, de 15 minutos, até conversas mais longas, de até 100 minutos.

Sendo assim, o texto segue com uma discussão teórica da História Local enquanto produção historiográfica, mas também como um método de ensino de história, ou seja, uma opção metodológica que preza pela liberdade pedagógica, enquanto professor e aluno pesquisador. Na sequência, segue uma discussão da configuração e formação identitária, proporcionada a partir do ensino e do conhecimento da História Local. 


\title{
Compreendendo a História Local
}

O início da elaboração e construção de histórias das localidades, ou mesmo das municipalidades, ocorreu a partir do trabalho dos chamados memorialistas, que se aproximavam do interesse dos acontecimentos do seu lugar e que, via de regra, por razões pessoais, começaram a reunir fontes e registrar o que entendiam ser sua história. Embora carregados de boas intenções, essa escrita não observava os aspectos científicos da escrita historiográfica. Provavelmente, é por isso que cada município tem alguma produção relativa à sua história, ao seu passado e à sua cultura, ainda que com fragilidade científica.

\begin{abstract}
A história local tem uma posição marginal na historiografia brasileira. Sua escrita predominantemente diletante e sua narrativa demasiado subjetiva parecem ser as principais responsáveis pelo seu descrédito em círculos acadêmicos, embora ainda seja grande a preferência que ela goza junto ao público leigo e avesso, muitas vezes, à linguagem hermética dos historiadores profissionais. ${ }^{1}$
\end{abstract}

Ainda que a História Local não tenha sido uma discussão que estivesse no topo das reflexões acadêmicas, em "República em migalhas - História Regional e Local", Silva ${ }^{2}$ já perpassava a reflexão, justificando a necessidade de opção metodológica que privilegiasse as fontes regionais. Por um lado, naquele momento, a referência não tinha tanta visibilidade para o local, por outro lado, se constitui num trabalho que caracterizava a História Regional e a diferenciava da Local, esclarecendo que cada abordagem merece um tratamento específico.

Conforme Silva ${ }^{3}$, os estudos históricos, enquanto corrente historiográfica que contempla a História Regional e a História Local, são temas que se entrecruzam e colocam ao pesquisador uma série de dúvidas de caráter conceitual e metodológico. Também existe diferença entre o que se entende como História Local para o ensino, isto é, de forma didática e metodológica, com o protagonismo do professor, e o que se entende como História Local para a pesquisa historiográfica, com o protagonismo do historiador.

Sob o ponto de vista teórico e metodológico, é fundamental diferenciar a História Local e a História Regional quanto ao campo de observação, que são radicalmente distintos. Por isso, os textos contidos em Silva ${ }^{4}$ favorecem e exploram essas perspectivas metodológicas de Região e História, tendo em vista que trazem uma amostra latente dos problemas da História Regional, constituindo um aporte teórico fundamental para pesquisas historiográficas com abordagens regionais, diferenciando o que não faz parte do local.

Vinte anos mais tarde, Barros ${ }^{5}$ defende que a História Regional constitui-se em uma maneira de pesquisar, abordar e escrever a História através de um recorte espacial, que pode ser associado ou desassociado do recorte administrativo, se referindo "a um recorte 
antropológico, a um recorte cultural ou a qualquer outro recorte proposto pelo historiador, de acordo com o problema histórico que irá examinar", , no sentido de escrever e produzir com o uso das fontes regionais.

Neste sentido, uma questão que diferenciaria a História Regional da História Local seria a comparação, uma vez que esta última teria uma perspectiva de estudar "a realidade micro localizada por ela mesma". ${ }^{7}$ Nesse ponto, é necessário ter cuidado ao se referir à microlocalização, porque não se pretende igualar com a micro-história, a qual não precisa necessariamente estudar um espaço físico, mas está associada ao "modo como o historiador vê". 8 Já a História Local estuda um lugar ou uma perspectiva de comunidade com seus diversos aspectos. ${ }^{9}$

Neste diálogo com Silva ${ }^{10}$ e Barros ${ }^{11}$, que aprofundam a diferenciação entre História Regional e Local, também participa Callai ${ }^{12}$, que já dizia, anos antes, que a História Local "é uma escala de análise que permite que tenhamos próximos de nós todos aqueles elementos que expressam as condições sociais, econômicas, políticas de nosso mundo", estudadas por um local. Em outras palavras, se fala de um lugar que guarda muitas relações de sociabilidades, marcado pela proximidade e pela contiguidade das relações entre os sujeitos que as estabelecem. Além disso, ao estudar o lugar, aplicamos um recorte de análise e reflexão.

Basicamente, o que difere a História Regional da História Local é o recorte geográfico, por isso, frequentemente, se fala na História Local como a história do entorno, do mais próximo, do bairro ou da cidade. Diante disso, um dos cuidados importantes com esses estudos é a identificação do conceito de espaço e de território. Simultaneamente, ao considerar que a História Local está relacionada e inserida em uma história global e nacional, ela se caracteriza pela valorização dos particulares, das diversidades. Nesse sentido, se constitui num ponto de partida para a formação de uma identidade local que valoriza o local/lugar. ${ }^{13}$

Isso posto, considera-se que não raramente o recorte territorial da História Local pode ultrapassar os limites do município, não apenas como um dado disperso, mas como parte de um todo mais complexo. Ainda assim, entende-se que cada lugar tem suas especificidades e precisa ser entendido por meio da série de elementos que o compõe e de suas funções. ${ }^{14}$ Assim, este trabalho pressupõe que a História Local considera o recorte territorial e o espaço vivido do município que, conforme Callai:

De um ponto de vista, pode-se considerar o município como LOCAL onde, pois é um determinado espaço com limites muito precisos, possui uma população que se 
identifica com o nome do próprio município, tem uma história sua, própria, tem o poder público instituído e responsável pelo bom andamento do mesmo. ${ }^{15}$

Baseando-se na concepção das "verticalidades e horizontalidades" de Milton Santos, a proposta de ensino da História Local é no sentido horizontal, pois é na horizontalidade que o local é abordado e pode ser compreendido. De acordo com Santos ${ }^{16}$, "os lugares também se podem fortalecer horizontalmente, reconstruindo, a partir das ações localmente constituídas, uma base de vida que amplie a coesão da sociedade civil, a serviço do interesse coletivo". Ferreira e Oliveira ${ }^{17}$ ressaltam a importância de não se isolar, ao estudar a História Local.

A história local só tem valor plenamente explorado se trabalhado com escalas que sejam intercambiadas e sobrepostas para que os alunos possam perceber justamente onde o local e o geral se distanciam e se aproximam. ${ }^{18}$

Portanto, essa afirmação chama a atenção para o fato de que, ao estudar História Local, é necessário manter as relações com as outras escalas mais gerais de compreensão dos acontecimentos, para se ter uma visão mais ampla do que ocorreu na história. Percebe-se que é possível estudar o local, se posicionar e acompanhar os movimentos históricos que perpassam ao longo dos períodos. Sendo assim, nesta pesquisa, a História Local é entendida como uma modalidade de estudos históricos que opera na escala de análise dos acontecidos no município. Ainda, considera a construção de processos interpretativos sobre as diferentes formas de como os atores sociais se constituíram historicamente dentro do município. Interessa-se pelos modos de viver, coletivos e individuais, dos sujeitos e grupos sociais situados nestes espaços que são coletivamente construídos e representados.

A partir desta perspectiva, se realizou a pesquisa e se percebeu que a visão dos entrevistados ia ao encontro dessa construção teórica. Num primeiro contato com eles, no momento de contextualização da pesquisa, os entrevistados, especialmente os gestores, manifestaram a sua insegurança em relação ao tema. Iniciaram a conversa esclarecendo que não sabiam muita coisa da História Local dos seus municípios, mas que queriam colaborar para mudar essa realidade. Já os professores, sobretudo os formados em cursos de História, foram mais pontuais e conceituais.

Assim, quando indagados sobre o que entendem sobre História Local, os professores e o gestor de Herveiras responderam que:

História Local é trabalhar as origens do município, provavelmente desde a origem da pré-história até os dias atuais, para entender como se deu a formação do município, desde o princípio (Grifo da pesquisadora). ${ }^{19}$

História Local é a que fale da colonização, fale como se construiu a sociedade local, dos aspectos culturais que estão enraizados e incorporados na cultura da região, por exemplo, a sociedade de grupos de danças gaúchas (Grifo da pesquisadora). ${ }^{20}$ 
Eu entendo que História Local é aquilo que vai contar a história de formação de um local, a história de um povo, município, do que vai ficar pra gente também levar isso. E o início de tudo. Tudo teve seu começo e daí se criou algumas histórias que a gente vai passando de geração para geração (Grifo da pesquisadora). ${ }^{21}$

As duas falas acima sintetizam a percepção do conjunto dos entrevistados que possui uma concepção de História Local de acordo com o que apontou Barros ${ }^{22}$, ou seja, um estudo do local, uma perspectiva de comunidade em seus diversos aspectos culturais, sem mencionar fatos heroicos e lendários. Os depoimentos apresentados condizem com as conclusões de Ortiz $^{23}$, que valorizam os aspectos culturais de um local. Também dialogam com Flores ${ }^{24}$ e Lencione $^{25}$, que enfatizam os modos de viver de um povo sob um território, seja ele vivido, seja ele administrativo.

Em Rio Pardo, a equipe de gestão e os professores seguem nesta mesma direção, conforme pode ser observado abaixo, a respeito dos seus entendimentos de História Local:

A história mais próxima... História da família... Do distrito... As lendas... A construção das igrejas e da primeira escola... A participação da comunidade na construção (Grifo da pesquisadora). ${ }^{26}$

Entendo que é o conhecimento de muitos fatos históricos de descobertas de patrimônios, das batalhas, lutas e conquistas que contam e encantam a nossa região (Grifo da pesquisadora). ${ }^{27}$

Dessa forma, novamente se constatou que a concepção de História Local possui o recorte de território municipal, porém é uma concepção que evidencia feitos heroicos, não apresentando, nestes discursos, visibilidade das condições históricas, sociais, econômicas e políticas que, conforme Callai $^{28}$, devem fazer parte dessa escala de análise. Para Souza e Silva $^{29}$, essa narrativa demonstrou a força ainda presente da herança eurocêntrica e heroica no ensino de história.

Como Rio Pardo é um município com uma área territorial extensa, um professor de uma escola municipal que fica distante da sede afirmou que compreendia a História Local como da "localidade, o lugar onde vivem, as comunidades". ${ }^{30} \mathrm{Na}$ sua compreensão do que é a História Local, ele traz um recorte dos aspectos que lhes são mais próximo, isto é, de localidade e nem tanto de município. Com essa mesma fala, também foi possível verificar que nas políticas e nas práticas pedagógicas do sistema educativo de Rio Pardo, se contemplou o recorte territorial nos limites municipais, contudo isso ainda não é suficiente para aproximar os estudantes da história do município, especialmente das localidades. Os estudantes até podem conhecer a narrativa histórica municipal ocorrida na sede, mas não aquela da sua localidade. 
Rio Pardo é tido e reconhecido como um município histórico no estado e, consequentemente, como tal, construiu sua narrativa carregada de eventos heroicos e de importância nacional. A experiência de Herveiras foi diferente, porque a cidade tem apenas 24 anos de emancipação administrativa, e não possui visibilidade na narrativa histórica estadual. Assim, ao se preocupar com sua história, o grupo entrevistado demonstrou interesse em conhecer os aspectos culturais da formação do seu povo, já conscientes de que não se sentem representados na narrativa histórica regional, indicando a necessidade e a importância do ensino e da pesquisa da História Local.

Dadas às discussões apresentadas até aqui, combinando análises teóricas com pesquisas empíricas, que diferenciaram os estudos históricos locais dos regionais, se entende, portanto, que o ensino de História Local pode ser uma estratégia/método de abordagem para ensino de história. Nessa ótica, se segue a concepção de que "os métodos de ensino são ações do professor pelas quais organizam as atividades de ensino e dos alunos para atingir objetivos do trabalho docente em relação a um conteúdo especifico". ${ }^{31}$ Por isso, é relevante pensar na possibilidade de uma ação prática e próxima ao cotidiano escolar. O ensino de História Local, na perspectiva de um método de ensino, é uma oportunidade de ensino e aprendizagem na linha horizontal entre professor e aluno.

Além disso, ao se colocar na defesa do ensino de História Local como um método, é necessário considerar as diversas linhas interpretativas e as problemáticas na construção da narrativa de cada lugar. Vale ressaltar que dificilmente o material de base com que os professores trabalham consegue dar conta das especificidades daquele território, sendo mais viável e significativo se valer de trabalhos escolares temáticos que partem de elementos ou acontecimentos da localidade. ${ }^{32}$ Nesse sentido, os acontecimentos de conhecimento e relevância para os alunos devem ser considerados, como a construção ou a história de uma estrada, uma ponte, uma igreja e, a partir desta atividade, estudar o seu local e estabelecer relações com as escalas e os tempos.

Conforme Pacheco ${ }^{33}$, no processo educativo, a prioridade se centra na problematização e não em oferecer o fato histórico dado ao aluno.

[...] O professor de história não deve se preocupar em ensinar como um fato realmente aconteceu, mas sim em problematizar como e por que se elegem determinados eventos para figurar a memória social e os efeitos dessa seleção na sociedade atual e na comunidade local. ${ }^{34}$

Diante de tal contexto, o aluno será instigado a questionar as narrativas dadas, desenvolvendo ou ampliando sua criticidade nas fontes históricas, desencadeando um 
processo investigativo para melhorar a construção do seu conhecimento. Nasce um aluno historiador, embora não seja a função da disciplina de história na escola formar historiadores, ainda assim ela pode despertar nos estudantes a atitude historiadora. O estudante fará isso a partir do seu local, desde sua infância, edificando condições para que, à medida que venha a adquirir maturidade, possa ser capaz de compreender, questionar e criticar outros períodos da história da humanidade.

A construção deste aluno com atitude historiadora permite e provoca a observação direta e próxima das fontes históricas, no que a História Local oferece maiores vantagens, seja enquanto apropriação de conhecimento histórico, seja enquanto método de ensino. Conforme Callai:

A História Local - sempre entendida como integrante de uma totalidade - é a mais viável para ser estudada pelos alunos em termos de fontes: é possível visitar acervo de documentos sobre a localidade; entrevistar pessoas importantes do ponto de vista histórico; observar as marcas deixadas no espaço pelas sucessivas gerações. ${ }^{35}$

Embora muitos municípios ainda não disponham de políticas memorialistas e arquivistas, a própria pesquisa escolar e o diálogo com a comunidade mobilizam a população para que se passe a valorizar e preservar esses materiais, o que possibilita relações específicas entre o passado, o presente e o futuro. Diante disso, Pinsky ${ }^{36}$ sugere formas de pesquisa e estudo, com a iniciativa do professor, como os trabalhos com memórias, sites, textos da macro-história e até mesmo a observação direta das sobrevivências e permanências através dos trabalhos de campo. Tais iniciativas se enquadram muito bem nos parâmetros da História Local.

Os professores de História, para levar às salas de aula a História Regional e Local, terão que virar pesquisadores. Ensino e pesquisa, teoria e prática terão que ser definitivamente associados, respeitando-se, é claro, as situações concretas vividas pelos profissionais da História. O que não se poderá fazer é ficar de braços cruzados, à espera de que alguma universidade ou algum pesquisador consagrado produza material didático suficiente para atender às demandas dos professores espalhados pelo Brasil, país tão grande e multifacetado. ${ }^{37}$

Posto isso, é importante mensurar que iniciar um trabalho com História Local é desafiador. De acordo com Ferreira e Oliveira,

[...] um trabalho com a História Local é uma ótima oportunidade para atuação dos próprios professores e alunos como sujeitos de produções do conhecimento eleito como objeto de estudo, atendendo também as discussões psicopedagógicas que prezam por uma educação centrada na produção da autonomia, da responsabilidade e da proatividade dos alunos. ${ }^{38}$

O ensino de História Local, pensado desta forma, se integra e cumpre com o que preconizam as políticas nacionais de educação, as quais prezam pela diversidade de recursos de ensino e pela construção de sujeitos críticos, ou seja, conforme apresentam os Parâmetros 
Curriculares Nacionais (PCNs), onde a História Local é vista "como recurso pedagógico privilegiado [...] que possibilita aos estudantes adquirirem, progressivamente, o olhar indagador sobre o mundo de que fazem parte"39, propiciando o conhecer para pertencer.

Em razão disso, o ensino de História Local como uma escolha pedagógica está amplamente relacionado aos propósitos da disciplina escolar de história, como um campo de memória para construção do conhecimento histórico e das identidades, por ser pensado e adaptado para o local.

A disciplina escolar de História, na grade curricular do ensino básico, sempre esteve associada à tarefa de reproduzir uma determinada narrativa sobre o passado que servisse ao propósito de construção da identidade nacional no presente, à afirmação de laços simbólicos que consolidassem nos alunos a noção de pertencimento a uma mesma comunidade de sentidos. ${ }^{40}$

Por consequência, o ensino de História Local é valorizado também como estudo do meio, que se vale de diversos temas, como a própria comunidade escolar, sua localidade, as instituições religiosas, elementos que envolvem aspectos da saúde, educação, lazer da população, entre outros, a partir dos seus lugares de memória. Nessa mesma direção, se indaga se essas discussões teóricas sobre a História Local e o seu ensino contribuem para a construção das identidades locais e das individuais.

\section{Construções identitárias}

A construção de identidades, em geral, está relacionada aos acontecimentos históricos e às relações socioculturais de um determinado território, bem como à forma que é apresentada e à memória existente e/ou construída. Ao mesmo tempo, interagem com os aspectos globais. De um lado, a globalização proporcionou a circulação de elementos culturais do mundo todo, permitindo o contato imediato de povos com culturas diferentes. De outro lado, gerou um crescente movimento local de autoafirmação, com a valorização das características específicas, via revalorização do patrimônio cultural e, por conseguinte, da identidade local.

Para abordar as questões de identidades é necessário estabelecer relações com outros aspectos correlatos, como a cultura, que é entendida como os modos de viver de uma determinada população. Segundo Ortiz $^{41}$, a cultura é vista amplamente e é composta por elementos materiais e imateriais de um povo, transmitidos ou compartilhados, que atuam e influenciam os diversos aspectos do seu modo de vida. Cada povo vive de acordo com as regras da sua cultura, que nem sempre estão escritas, mas são transmitidas e regulam as práticas culturais e até mesmo as relações econômicas. 
Portanto, esse trabalho segue a perspectiva de cultura de Ortiz ${ }^{42}$, entendendo que ela está amplamente vinculada ao desenvolvimento e ao processo de (re) construção das identidades locais, visto que estes elementos refletem os modos de vida de um povo que vive em determinado lugar/local. Embora possam ter pontos semelhantes, os modos de vida de uma população não ficam imutáveis e não se restringem de forma extremamente fixa a determinado local. Também se compõem pelos aspectos substantivos da cultura, apresentando troca cultural, em particular, pela expansão das culturas através das tecnologias e da revolução da informação.

O avanço da globalização e os novos mecanismos de comunicação global que se desenvolvem de forma cada vez mais acelerada trouxeram à tona no campo educacional uma nova e justificada preocupação: a globalização como fator de massificação dos indivíduos e de homogeneização das sociedades, o que pode vir a suprimir a identidade local e as singularidades. Considerando essa realidade, se evidencia cada vez mais a importância da História Local como um dos elementos na construção da identidade territorial e local.

Conforme Hall ${ }^{43}$ e Larrain ${ }^{44}$, essas mudanças culturais globais estão criando uma rápida mudança social, aniquilando as particularidades e as diferenças locais e produzindo em seu lugar uma cultura mundial homogeneizada, com predominância de feições ocidentalizadas. De modo geral, um mix cultural com alternativas híbridas de sociedades multiculturais e culturalmente diversificadas. ${ }^{45}$ Para Bauman ${ }^{46}$, a "modernidade líquida" coloca a identidade em um processo de transformação que provoca fenômenos como a crise do multiculturalismo, o fundamentalismo islâmico ou as comunidades virtuais da Internet. Por isso, embora ainda se encontrem dificuldades, ensinar e aprender a respeito da formação social e econômica local é fundamental no processo de (re) construção das identidades. Com isso, neste "contexto atual histórico, no qual cada vez mais as identidades são líquidas, fluídas" ${ }^{\prime 7}$, torna-se desafiador relacionar local/global, singular/plural, universal/diverso em sala de aula.

Sob os efeitos da globalização, é extremamente difícil para o cidadão comum ter uma imagem mais precisa do passado histórico sem tê-lo tematizado no interior de uma "cultura herdada", que inclui panoramas e costumes de época. Diante de tais elementos, cabe ao ensino, particularmente da História Local, a competência de ajudar na (re) construção ou identificação da sua cultura para, novamente, na construção ou identificação das identidades, suavizar os impactos da globalização nas identidades locais. ${ }^{48}$ 
Dialogando com os conceitos de identidades e cultura, Larrain ${ }^{49}$ (2003) explica que ambos envolvem uma narrativa sobre histórias pessoais e de grupos, comunidades, locais, que estuda a cultura e entende as identidades, que reconhece as formas simbólicas as quais fazem parte da cultura e da identidade de um povo.

É um discurso sobre si mesmo ou sobre o grupo na interação com outros grupos, que só é possível por meio de uma estrutura de significados comuns e da linguagem. Estudar a identidade é estudar como as formas simbólicas são mobilizadas para sua construção. $^{50}$

Partindo de um consenso geral, o conceito de identidade sugere a identificação de alguma coisa ou alguém. Nessa perspectiva, e unindo vários alguéns, temos os grupos representativos e identitários. Hall ${ }^{51}$ também sugere uma desconstrução desse conceito de identidade, no entanto reconhece que ainda não existe um novo conceito, uma nova palavra capaz de substituir o conceito de identidade de forma completa, portanto, a definição ainda deve ser explorada com suas críticas.

Dentre todas as complexidades do conceito de identidade trazidas por Hall ${ }^{52}$, uma delas faz diferenciação entre identidade e identificação, muito embora a identidade possa, por muitas vezes, originar-se de um processo de identificação.

Nossas identidades culturais refletem as experiências históricas em comum e os códigos culturais partilhados, que nos fornecem, a nós, como um "povo uno", quadros de referências e sentidos estáveis, contínuos, imutáveis sob as divisões cambiantes e as vicissitudes de nossa história real. ${ }^{53}$

Relações de identidades são, portanto, construídas a partir dos sujeitos, os quais sempre andaram juntos com os processos e dão subsídios para a construção dos processos identitários, ao ponto que Hall ${ }^{54}$ explica que o conceito de identidade abordado não é essencialista e sim estratégico e posicional. Diante do exposto, a identidade deve ser identificada e valorizada para que os sujeitos possam se reconhecer na sua identidade coletiva ou se excluir dela, caso essa não o represente, até porque as identidades culturais são múltiplas: nacional, pessoal, territorial, regional e plural. $\mathrm{Na}$ perspectiva dos estudos históricos locais, isto é, a abordagem do presente texto, se enfatiza a identidade territorial e local, flexibilizando a discussão de que várias identidades podem compor e compõem o mesmo sujeito.

O migrante, por exemplo, carrega consigo a identidade do seu território de origem, pois ele sai do território, mas o território não sai dele. Neste cenário, surgem novas identidades multiculturais e multi-identitárias, proporcionando o surgimento de novos conceitos. Por isso, Haesbaert ${ }^{55}$ critica o termo desterritorialização, usado para explicar o movimento de deslocamento da cultura do seu território de origem, pelo qual a identidade vai 
além do território geográfico. Na sua visão, essa realidade nada mais é que "as noções de identidade social e identidade territorial, concluindo com novas questões sobre as identidades transterritoriais, mas complexas, num mundo globalizado",56.

Haesbaert ${ }^{57}$ também problematiza dizendo que a identidade é praticamente indefinível, polissêmica, abstrata e moldada pela construção simbólica, carregada de subjetividade e de objetividade. A identificação de uma identidade se dá em relação a outras identidades, com a complexa relação de escalas territoriais e valorizações. Portanto, retomando as discussões sobre o deslocamento da identidade do território, se concluí que todo território pode ter uma identidade e que também existe identidade sem território, que são as identidades universais. Diante desta nova realidade, se configura uma nova identidade territorial que é resultante de diversos fatores, como migrações e efeitos de globalização.

Com esse novo desenho de identidades, existe um discurso que propõe uma ideia de (re) territorialização e (re) construção imaginária da identidade. Nessa proposta, Haesbaert (2013) argumenta que os projetos e discursos sobre a valorização das identidades e a noção de pertencimento à identidade cultural, territorial e social são embasados muitas vezes na História Local, Regional e Nacional e nos movimentos sociais que podem dar origem a novas identidades, como é o caso do movimento negro, movimento feminista, movimento LGBT, cuja sigla significa lésbicas, gays, bissexuais, travestis, entre outros. Aqui é possível ver que a identidade pode não ter território, mas o território pode ter uma ou mais identidades, mencionadas como identidades plurais.

Por sua vez, o termo território possui diversas conceituações, provindo "do latim, territorium, que, por sua vez, deriva de terra e significa espaço de terra apropriado". 58 Para direcionar o entendimento do trabalho e propor uma compreensão acerca do território, é importante considerar que espaço e território são coisas diferentes, mas que se relacionam. Sua relação se dá pela construção social que ocorre sobre o espaço e constrói o território, o qual "surge, portanto, como resultado de uma ação social que, de forma concreta e abstrata, se apropria de um espaço (tanto física como simbolicamente), por isso denominado um processo de construção social". 59

A partir de uma abordagem mais culturalista, o espaço é usado e apropriado pela população, que também integra o território, ou seja, um espaço vivido por uma construção social. Segundo Flores ${ }^{60}$, "sua identidade cultural é uma ação coletiva, determinada em conjunto com um marco institucional que regula as atividades dos atores locais que participam do processo de construção". Nesse sentido dado pelo autor, os vínculos culturais 
são a soma de todos os elementos culturais, ambientais e produtivos que têm um efeito conjunto adquirindo uma qualidade territorial, que também recebe o nome de território construído e vivido.

Também existe o território dado, que é aquele que conhecemos geograficamente e politicamente através de mapas e determinações políticas. Esse não observa as características culturais e as experiências vividas, mas é "estabelecido de cima para baixo" "61 , obedecendo a decisões político-administrativas expressas, geralmente, pelas decisões de governos.

Portanto, se entende que o território está em constante transformação, não unicamente por seus limites territoriais, mas também através de seus "limites" culturais, naturais, históricos e sociais, ou melhor, as suas diversidades, singularidades e particularidades. Esse território construído também é influenciado, pressionado por forças universais compreendidas, de certa forma, até com o poder e as forças da globalização. Esse entendimento é mais bem esclarecido nas palavras de Etges:

[...] o território tem que ser visto como algo que está em processo, uma formaconteúdo, o traço de união entre o passado e o futuro imediato. Ele tem que ser visto como um campo de forças, como um lugar de exercício, de contradições entre o vertical e o horizontal, entre o estado e o mercado, entre o uso econômico e o uso social dos recursos $[\ldots]^{62}$

No presente trabalho, o olhar está mais voltado para o território vivido do que para o território dado, sendo que ambos precisam estar fortalecidos, assim como a sociedade e a natureza. Além disso, o território possui uma formação econômica e social sob um invólucro histórico determinado. Diferentemente do território dado, o construído é o "definido por elementos escolhidos pelos próprios atores locais, de forma participativa, de baixo para cima". ${ }^{3}$

Retomando a relação com as escolas, se sabe que elas estão inseridas em um território construído. Assim, no contexto escolar, os conhecimentos do território podem e devem ser valorizados na perspectiva de potencializar a região. Os estudantes estão inseridos em um território que espelha uma cultura local. É importante que tanto no ensino da Geografia, como no da História Local, isto é, o caso aqui detalhado, seja explorada em sua totalidade, dialogando com as escalas local, regional e global, como preveem os Parâmetros Curriculares Nacionais:

Os conteúdos de História para o segundo ciclo enfocam as diferentes histórias que compõem as relações estabelecidas entre a coletividade local e outras coletividades de outros tempos e espaços, contemplando diálogos entre presente e passado e os espaços locais, nacionais e mundiais. ${ }^{64}$ 
Considerando que as escolas devem contribuir na formação da identidade territorial regional, o ensino de História Local faz parte desse processo de construção da identidade. Conforme Flores $^{65}$, o território também passa a ser delimitado pela identidade territorial e regional construída.

O território é delimitado pela identidade, pelo interesse comum na resolução de um problema ou resultado esperado: delimitação de uma área na qual os atores ou grupos sociais exercem domínio e possuem o interesse comum de proteger, preservar, valorizar o que tem "de seu" neste espaço, seja na esfera cultural, histórica, ambiental, das potencialidades econômicas, etc. ${ }^{66}$

É possível dizer que "o local é uma janela para o mundo"67 e a História Local se torna fundamental para a (re) construção e identificação das identidades locais, tão importantes mesmo em época de globalização e de hibridismos das identidades. Por isso, o presente artigo propõe a História Local como método de ensino ou, ainda, como uma forma de abordagem do estudo da história. A argumentação está baseada no fato de que o aluno precisa, primeiramente, se reconhecer como sujeito, se encontrar ou se construir na sua identidade para, posteriormente, se posicionar na sociedade, através da leitura do contexto, do seu local, antes da leitura do texto mundial.

Assim, as questões de identidades se constituem em uma discussão de via dupla, pois se as identidades são (re) construídas através do ensino de História Local, tampouco haverá políticas e democratização desse ensino se não houver identidade e pertença ao seu local. Desta forma, narrativas históricas dadas e acabadas interrompem o processo de se reconhecer e se construir como sujeito e cidadão.

A partir desse embasamento teórico apresentado e tendo como referência as entrevistas comentadas que seguem logo a seguir, se verificou que a (re) construção da identidade local é estruturada por três pilares:

FIGURA 1: (RE) CONSTRUÇÃO DA IDENTIDADE LOCAL

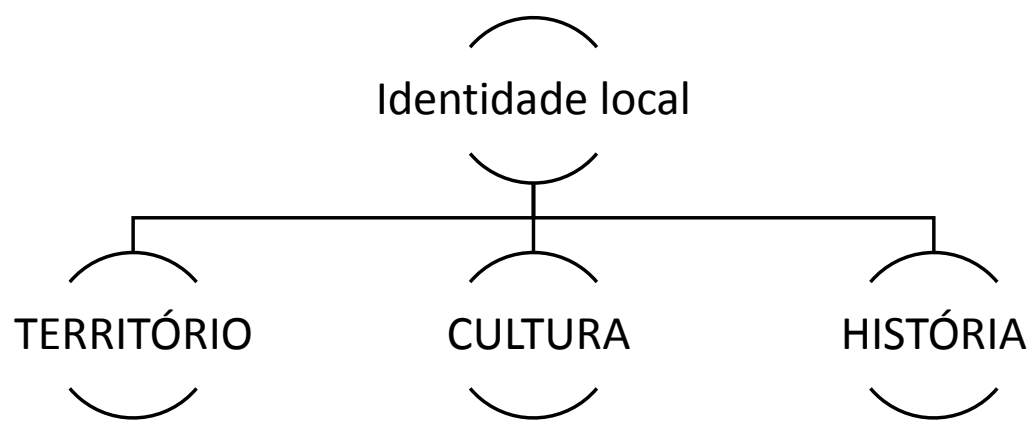

Fonte: Autores. 
Em relação ao pilar do território, é necessário que os estudantes saibam de qual território estão falando, enquanto que o da cultura aponta para indispensabilidade de se conhecer as diversas culturas que constituem aquele território. Para completar a tríade dos pilares, é imperativo que os estudantes tenham conhecimento da história daquele território e daquelas culturas. A referida conclusão baseou-se na experiência de Herveiras, em que a narrativa histórica não se constrói e nem se solidifica, pois professores e gestores duvidam da credibilidade e, por consequência, não se identificam com a narrativa dada.

Os professores sabem que a narrativa existente não constitui a identidade de Herveiras, mas, ao mesmo tempo, não conseguiram ajudar a construir uma ressignificação da identidade. Porém, ao menos reconhecem a qual grupo identitário não se pertence e se busca os semelhantes para uma tentativa de identificação.

Eu até acredito que Herveiras tenta se centrar em uma identidade alemã que hoje não tem relação com o município, ela tem relação com o município de Sinimbu, de Vale do Sol, que são municípios vizinhos e que tem uma própria constante cultural com o município de Herveiras. (Grifo da pesquisadora). ${ }^{68}$

Nesta situação, acontecem as condições de pertencimento aos grupos representativos que foram expostas por Larrain ${ }^{69}$, bem como as condições cultural e histórica sugeridas por Hall. $^{70}$ Como professores e estudantes não se identificam com a narrativa apresentada, se sugere começar a estudar pela comunidade escolar, através da História Local, propiciando que os alunos pesquisem, se reconheçam ou se distingam do grupo maior e das identidades e, dessa forma, percebam a existência de outros agentes participantes da formação histórica e cultural do território. Foi, por exemplo, o aspecto que um professor da rede municipal de Herveiras destacou. Segundo o entrevistado, "é importante para os alunos reconhecerem que não apenas os imigrantes europeus vieram para cá e foram os responsáveis por construir o município. Existem muitos outros povos envolvidos". (Grifo da pesquisadora). ${ }^{71}$

Já em relação à cidade de Rio Pardo, mais precisamente em uma das escolas participantes da pesquisa, ocorre o não reconhecimento e pertencimento à identidade histórica e cultural do município. Em virtude da sua extensão territorial, a comunidade/localidade, que fica muito distante da sede e de sua população, não conhece a totalidade do município, não construiu sua identidade histórica interligada com a municipal, entretanto se reconhece com a identidade histórica e cultural do município vizinho, que está mais próximo. Tal situação remete ao que foi salientado por Haesbaert ${ }^{72}$ sobre a questão do pertencimento de território e da desterritorialização, discutida em páginas anteriores. Além disso, é importante ter presente 
que as identidades não obedecem aos limites políticos, administrativos e territoriais, mas expandem fronteiras.

A realidade de Rio Pardo é que, dentro do mesmo município, é possível encontrar mais de uma identidade que, como resultado, se configura nas múltiplas identidades históricas. Por isso, a História Local entendida como método de ensino, e não como reprodutora de narrativas, é capaz de democratizar o ensino de história e permitir que todas as identidades se reconheçam na formação do território municipal. Conforme relato do professor C da rede municipal, no ano de implantação da disciplina de História de Rio Pardo, houve resistência por parte dos seus alunos, mas, com o passar dos anos, ele sentiu mudança nesta postura. Quando a narrativa de Rio Pardo foi apresentada aos alunos, junto com a identidade que a acompanha, os estudantes da escola reafirmam a sua identidade local. Na lógica do que foi apresentado por Hall ${ }^{73}$ sobre representatividades, escolheram tomar ou não para eles aquela identidade.

Em Herveiras, para além do não pertencimento à narrativa da história existente, os professores também apresentam preocupação com a construção da identidade na perspectiva de que os estudantes tenham orgulho da vida cotidiana e do lugar onde vivem. Quando questionados sobre a forma como viam a construção das identidades, um professor afirmou que o ensino da História Local deve ou deveria colaborar na valorização do lugar do aluno.

Eles se valorizam no espaço deles... Eu tenho alunos que querem estudar e fazer a diferença no lugar aonde eles vivem. Lá no $4^{\circ}$ ano, eu tenho três alunos que querem ser agricultores e não querem ir embora (Grifo da pesquisadora). ${ }^{74}$

A situação que a professora traz é muito enriquecedora, no sentido de pensar sobre o pertencimento ao local, a construção da identidade, o posicionamento na sociedade e, consequentemente, na formação da cidadania. Assim, se percebe que por se tratar de um município essencialmente rural, os professores querem trabalhar a História Local, para desconstruir conceitos de que a vida melhor é no espaço urbano e, principalmente, garantir que ficar no meio rural, ou não, seja uma livre escolha e não uma decisão tomada no calor da pressão ou por falta de opções.

\section{Considerações finais}

A utilização do ensino de História Local enquanto um método de edificação de conhecimento sobre determinado lugar cria grandes possibilidades de construção da cidadania e da identidade, conforme demonstraram as pesquisas nos sistemas educativos municipais e estaduais de Herveiras e Rio Pardo. No caso da prática educacional e das vivências em 
relação ao município de Rio Pardo, na (re) construção da identidade local, se percebeu que a História Local deve levar em consideração os elementos culturais, conforme Ortiz ${ }^{75}$, que são estruturantes da narrativa histórica e que, sobretudo, deve considerar os elementos culturais do local, isto é, do território vivido, que vai além do território político administrativo, tal como apontam os estudos de Lencione. ${ }^{76}$

$\mathrm{Na}$ experiência de Herveiras, as práticas no ensino de História Local apresentaram boas considerações em relação à construção da identidade local. Através dos depoimentos dos professores, foi possível unir elementos que sugerem que os alunos se identificam naquilo que estudam e pesquisam em história, resultando na construção de identidades e de sujeitos livres, críticos, ativos, com consciência cidadã e democrática. Entretanto, este fato ocorre em função de iniciativas dos educadores em proporcionar momentos e estabelecer relações com a realidade próxima dos alunos e não por uma política e concepção intencional do poder público dos sistemas de ensino.

Por isso, o motivo das questões identitárias fecharem a discussão do ensino de História Local é que as políticas não devem violar o processo de (re) construção das identidades. Em outras palavras, as políticas para o ensino de História Local não devem eleger uma narrativa única e acabada e reproduzi-la sem questionamentos, mas devem dar conta de atender às demandas históricas e culturais de forma democrática e plural, permitindo a participação do maior número possível de representes da sociedade local na sua construção.

\section{Notas}

${ }^{1}$ CORREA, Sílvio M. de S. História local e seu devir historiográfico. MÉTIS: história \& cultura - v. 2, n. 2, p. 11-32, jul./dez. 2002, p. 11.

2 SILVA, Marcos A. da (Org.). República em migalhas - História Regional e Local. São Paulo: Marco Zero/CNPq, 1990.

${ }^{3}$ Ibid.

${ }^{4}$ Ibid.

${ }^{5}$ BARROS, José D’Assunção. O campo da História. Petrópolis: Editora Vozes, 2010.

${ }^{6}$ Ibid., p. 151.

${ }^{7}$ Ibid., p. 152.

${ }^{8}$ Ibid., p. 152-153.

${ }^{9}$ Ibid.

${ }^{10}$ SILVA, op. Cit.

${ }^{11}$ BARROS, op. Cit.

${ }^{12}$ CALLAI, Helena C.; ZARTH, Paulo A. O estudo do município e o ensino de História e Geografia. Ijuí: UNIJUÍ Ed., 1988, p. 11.

${ }^{13}$ PINSKY, Carla Bassanezi (Org.). Novos temas nas aulas de História. São Paulo: Contexto, 2018.

${ }^{14}$ LENCIONI, Sandra. Região e Geografia. São Paulo: Edusp, 1999.

${ }^{15}$ CALLAI; ZARTH, op. Cit., p. 17.

${ }^{16}$ SANTOS, Milton. A natureza do Espaço - técnica e tempo, razão e emoção. São Paulo: Hucitec, 1996, p. 194.

${ }^{17}$ FERREIRA, Marieta de M. OLIVEIRA, Margarida M. D (Cord.). Dicionário de Ensino de História. Rio de Janeiro: FGV Editora, 2019. 


\footnotetext{
${ }^{18}$ Ibid., p. 136.

${ }^{19}$ Professor C - Rede municipal de Herveiras.

${ }^{20}$ Professor C - Rede estadual de Herveiras.

${ }^{21}$ Gestor Municipal - Herveiras.

${ }^{22}$ BARROS, op. Cit.
}

${ }^{23}$ ORTIZ, Renato. Cultura e Desenvolvimento. Salvador: Políticas Culturais em Revista, 1(1), p. 122-128, 2008. Disponível em: http://www.portalseer.ufba.br/index.php/pculturais/article/view/3194/2304. Capturado em maio 2016.

${ }^{24}$ FLORES, Murilo. A identidade cultural do território como base de estratégias de desenvolvimento - Uma visão do estado da arte. Santiago, Chile: RIMISP, 2006. Disponível em: http://indicadores.fecam.org.br/uploads/28/arquivos/4069_FLORES_M_Identidade_Territorial_como_Base_as_ Estrategias_Desenvolvimento.pdf

${ }^{25}$ LENCIONE, op. Cit.

${ }^{26}$ Gestor Municipal - Rio Pardo.

${ }^{27}$ Professor A - Rede estadual de Rio Pardo.

${ }^{28}$ CALLAI; ZARTH, op. Cit.

${ }^{29}$ SOUSA, Israel S.; SILVA, Severino B. Por um ensino de História referenciado na Educação Popular. Revista História Hoje, vol. 5, no 9184. 2016. Disponível em https://rhhj.anpuh.org/RHHJ/article/view/32/178

${ }^{30}$ Professor A - Rede Municipal - Rio Pardo.

${ }^{31}$ LIBÂNEO, José Carlos. Didática. São Paulo: Cortez, 1990, p. 152.

${ }^{32}$ FERREIRA; OLIVEIRA, op. Cit.

${ }^{33}$ PACHECO, Ricardo de Aguiar. Ensino de História e Patrimônio Cultural - Um percurso docente. Jundiaí, SP: Paco, 2017.

${ }^{34}$ Ibid., p. 22.

${ }^{35}$ CALLAI; ZARTH, op. Cit., p. 12.

${ }^{36}$ PINSKY, op. Cit.

${ }^{37}$ Ibid., p. 146.

${ }^{38}$ FERREIRA; OLIVEIRA, op. Cit., p. 134.

39 BRASIL. Parâmetros Curriculares Nacionais: Geografia/Secretaria de Educação Fundamental. Brasília: MEC/ SEF, 1998, p. 9.

${ }^{40}$ PACHECO, op. Cit., p. 21.

${ }^{41}$ ORTIZ, op. Cit.

${ }^{42}$ Ibid.

${ }^{43}$ HALL, Stuart. A centralidade da cultura: notas sobre as revoluções culturais do nosso tempo. Cultura, Mídia e Educação - Educação \& Realidade. Porto Alegre, v. 22, n 2, p 15-46, jul./dez. 1997.

${ }^{44}$ LARRAIN, Jorge. El concepto de identidad. Revista FAMECOS, Porto Alegre, n. 21, p. 30-42, ago. 2003.

${ }^{45}$ HALL, op. Cit.

46 BAUMAN, Zygmunt. Identidade: entrevista a Benedetto Vecchi. Trad. Carlos Alberto Medeiros. Rio de Janeiro: Jorge Zahar. 2005.

47 FONSECA, Selva Guimarães. Didática e prática de ensino de história: Experiências, reflexões e aprendizagens. Campinas, SP: Papirus, 2013, p. 240.

${ }^{48}$ HALL, op. Cit.

${ }^{49}$ LARRAIN, op. Cit.

${ }^{50}$ Ibid., p. 32.

${ }^{51}$ HALL, op. Cit.

${ }^{52}$ Ibid.

${ }^{53}$ Ibid., p. 68.

54 Ibid.

55 HAESBAERT, R. Identidades Territoriais. In: ROSENDAHL, Z.; CORREAA, R. L. (Org.). Geografia Cultural: uma antologia Vol. II. 1ed. Rio de Janeiro: Editora da UERJ, 2013, v. II, p. 233-244.

${ }^{56}$ Ibid., p. 235.

${ }^{57}$ Ibid.

${ }^{58}$ FLORES, op. Cit., p. 36.

${ }^{59}$ Ibid., p. 4.

${ }^{60}$ Ibid., p. 14.

${ }^{61}$ Ibid., p. 36.

${ }^{62}$ ETGES, Virginia Elisabeta; DEGRANDI, José Odim. Desenvolvimento regional: a diversidade regional como potencialidade. RBDR, Blumenau, v.1, n.1, p. 85-94, abril. 2013, p. 91.

${ }^{63}$ FLORES, op. Cit., p. 36. 
${ }^{64}$ BRASIL, op. Cit., p. 46.

${ }^{65}$ FLORES, op. Cit.

${ }^{66}$ Ibid., p. 36.

${ }^{67}$ FONSECA, op. Cit., p. 244.

${ }^{68}$ Professor C - Rede municipal de Herveiras.

${ }^{69}$ LARRAIN, op. Cit.

${ }^{70}$ HALL, op. Cit.

${ }^{71}$ Professor C - Rede municipal de Herveiras.

${ }^{72}$ HAESBAERT, op. Cit.

${ }^{73}$ HALL, op. Cit.

${ }^{74}$ Professor A - Rede municipal de Herveiras.

${ }^{75}$ ORTIZ, op. Cit.

${ }^{76}$ LENCIONE, op. Cit. 


\section{Referências}

BARROS, José D’Assunção. O campo da História. Petrópolis: Editora Vozes, 2010.

BAUMAN, Zygmunt. Identidade: entrevista a Benedetto Vecchi. Trad. Carlos Alberto Medeiros. Rio de Janeiro: Jorge Zahar. 2005.

BITTENCOURT, Circe Maria Fernandes. Ensino de história: fundamentos e métodos. São Paulo: Cortez, 2009.

BRASIL. Parâmetros Curriculares

Nacionais:

Geografia/Secretaria de Educação Fundamental. - Brasília: MEC/ SEF, 1998.

CALLAI, Helena C.; ZARTH, Paulo A. O estudo do município e o ensino de História e Geografia. Ijuí: UNIJUÍ Ed., 1988.

CORREA, Sílvio M. de S. História local e seu devir historiográfico. MÉTIS: história \& cultura - v. 2, n. 2, p. 11-32, jul./dez. 2002.

ETGES, Virginia Elisabeta; DEGRANDI, José Odim. Desenvolvimento regional: a diversidade regional como potencialidade. $R B D R$, Blumenau, v.1, n.1, p. 85-94, abril. 2013.

FERREIRA, Marieta de M. OLIVEIRA, Margarida M. D (Cord.). Dicionário de Ensino de História. Rio de Janeiro: FGV Editora, 2019.

FLORES, Murilo. A identidade cultural do território como base de estratégias de desenvolvimento - Uma visão do estado da arte. Santiago, Chile: RIMISP, 2006. Disponível em:

http://indicadores.fecam.org.br/uploads/28/arquivos/4069_FLORES_M_Identidade_Territoria 1_como_Base_as_Estrategias_Desenvolvimento.pdf

FONSECA, Selva Guimarães. Didática e prática de ensino de história: Experiências, reflexões e aprendizagens. Campinas, SP: Papirus, 2013.

HAESBAERT, R. Identidades Territoriais. In: ROSENDAHL, Z.; CORRÊA, R. L. (Org.). Geografia Cultural: uma antologia Vol. II. 1ed. Rio de Janeiro: Editora da UERJ, 2013, v. II, p. 233-244.

HALL, Stuart. A centralidade da cultura: notas sobre as revoluções culturais do nosso tempo. Cultura, Mídia e Educação - Educação \& Realidade. Porto Alegre, v. 22, n 2, p 15-46, jul./dez. 1997.

LARRAIN, Jorge. El concepto de identidad. Revista FAMECOS, Porto Alegre, n. 21, p. 3042, ago. 2003.

LEMOS, Carlos A. C. O que é Patrimônio Histórico. Coleção Primeiro Passos. São Paulo: Editora Brasilense, 1981.

LENCIONI, Sandra. Região e Geografia. São Paulo: Edusp, 1999. 
LIBÂNEO, José Carlos. Didática. São Paulo: Cortez,1990

ORTIZ, Renato. Cultura e Desenvolvimento. Salvador: Políticas Culturais em Revista, 1(1), p. $2008.122-128$ Disponível em: http://www.portalseer.ufba.br/index.php/pculturais/article/view/3194/2304. Capturado em maio 2016.

PACHECO, Ricardo de Aguiar. Ensino de História e Patrimônio Cultural - Um percurso docente. Jundiaí, SP: Paco, 2017.

PINSKY, Carla Bassanezi (Org.). Novos temas nas aulas de História. São Paulo: Contexto, 2018.

SANTOS, Milton. A natureza do Espaço - técnica e tempo, razão e emoção. São Paulo: Hucitec, 1996.

SILVA, Marcos A. da (Org.). República em migalhas - História Regional e Local. São Paulo: Marco Zero/CNPq, 1990.

SOUSA, Israel S.; SILVA, Severino B. Por um ensino de História referenciado na Educação Popular. Revista História Hoje, vol. 5, $\mathrm{n}^{\mathrm{o}}$ 9184. 2016. Disponível em https://rhhj.anpuh.org/RHHJ/article/view/32/178

SOUZA, Rita de C. L. A história local e as suas abordagens nas salas de aula da rede municipal de educação de Nova Friburgo. Dissertação (Mestrado Profissional em Ensino de História) - Universidade Federal Fluminense, Instituto de Ciências Humanas e Filosofia, 2016. 